الجوانب الاقتصادية والتسويقية المرتبطة بطرق التظلب على مشكلات الفاقد الغذائي لبعض الصادرات والواردات الغذائية

\author{
عصام الدين عبدالرحمن \\ أستاذ بقسم بحوث تثبعيع الأغذية \\ بالمركز القومي لبحوث وتكنولوجيا الإثعاع \\ محمد السيد راجح \\ أستاذ متفرغ بقسم الاقتصاد الززاعي \\ كلية الزراعة - جامعة بنها \\ سعيد عباس محمد رشاد \\ أستاذ ورئيس قسم الاقتصاد الزراعي \\ إبراهيم محمود محمد مراد

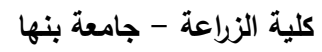

مدرس مساعد بقسم بحوث تثعيع الأغذية بالمركز القومي لبحوث وتكنولوجيا الإثعاع.

Corresponding author: Ibrahimmourad17121960@gmail.com

\begin{abstract}
المستخلص
يعد السعي نحو خفض الفاقد الكمي والنوعي لبعض الصادرات والواردات الغذائية مع تلافي المشاكل الصحية والبيئية والتنسويقية

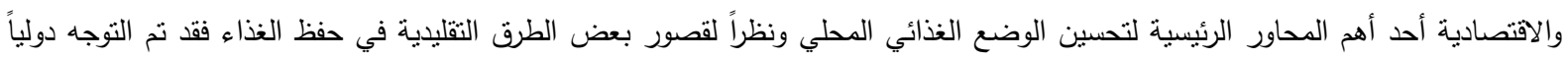

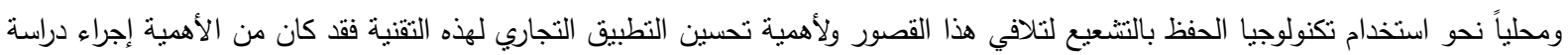
جدوى فنية وتسويقية لاستخدام تكنولوجيا التشعيع في حفظ الصادرات والواردات المصرية وقد هدفت إلى التعرف على الإمكانيات الفنبة لاستخدام

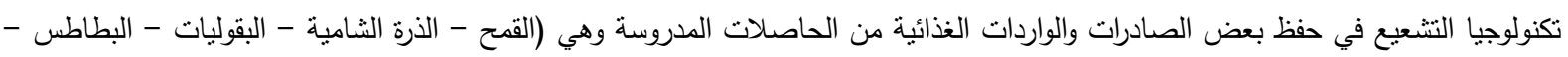

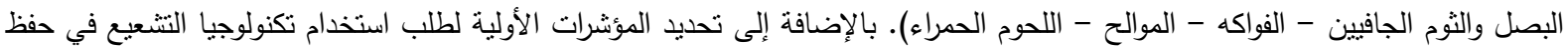
بعض الصادرات والواردات الغذائية وتثير أهم النتائج إلى أن الكمية المنوقع حفظها نحو ما يعادل 933 ألف طن سنوياً بجرعة تشعيعية 1 ك.

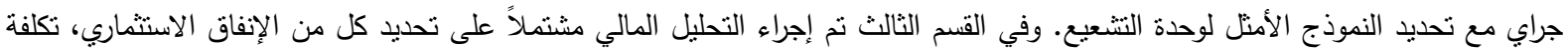

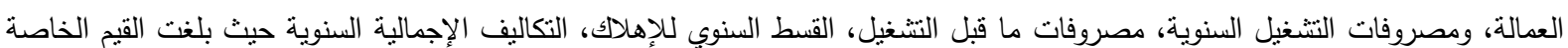

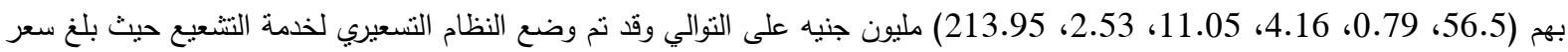

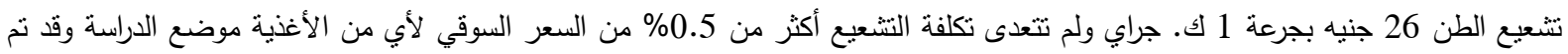

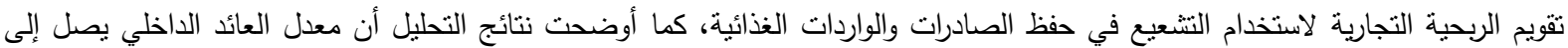
27، 21\% بينما فترة الاسترداد تصل إلى 3.4 سنوات، 4.4 سنة وذلك في كل من حالاتي التحليل الأساسي وتحليل الحساسية وقد تم تحليل

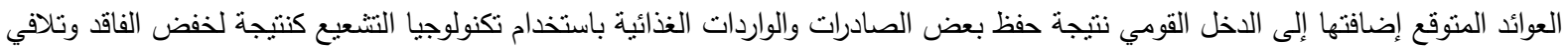
المشاكل الصحية والبيئية لطرق الحفظ الثقليدية.

يعد تحسين النطبيق النجارى لتقنية حفظ الأغذية بالتثعيع هدف أساسى للمجتمع باعتبار أن الحفظ بالطرق التقليدية المنبعة حالياً وبخاصة

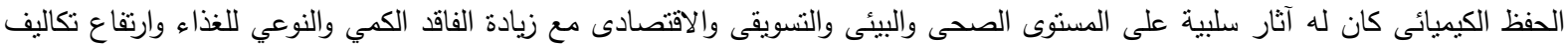

الحفظ.

وقد أصبحت تقنية الحفظ بالثتعيع احدى الحلول المطروحة محلياً ودولياً والمعتمدة دولياً من كل من منظمة الأغذية والزراعة (الفاو)

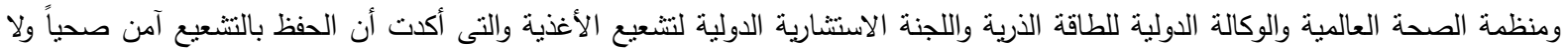

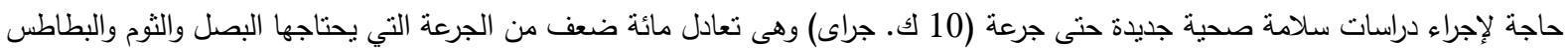

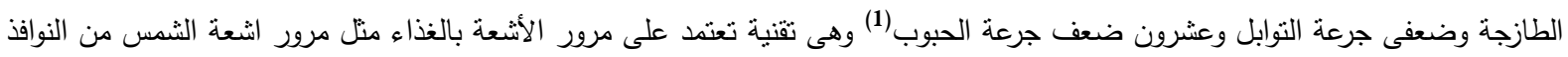
الزجاجية دون أن تنزك أى أثر ولكنها تطهر الغذاء من كافة الملوثات الميكروبية الفطرية والحشرية وتثقاوم التزريع والتدهور وتشاعد على إطالة فترة

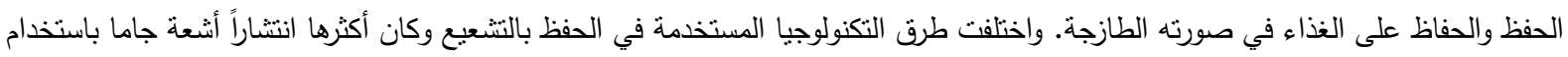
الكوبالت (60) ولكن الآن انتثرت النقنية الأحدث باستخدام المعجلات الإلكترونية والتى تتنج الأثشعة الإلكترونية، اشتعة (إكس)(2) وحيث أن هناك

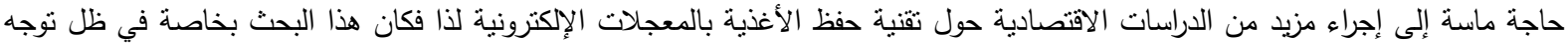

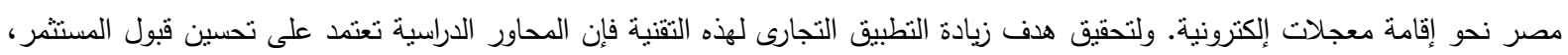
لأن قبول المستثر يعتد على تقديم الدراسة الاقتصادية الخاصة بجدوى الاستثمار للتطبيق التجارى لهذه التقنية وكنلك للحصول على التراخيص اللازمة فإن ذلك يستكى تحقيق قبول المجتمع لهذه التقنية المستحدثة، والتأكد من سلامتها الغذائية والصحية. ومن أجل ذلك أجري هذا البحث بغرض التعرض للأسباب سالفة الذكر والعمل على تحقيقها حتى نضمن قبول المستهلك لهذه الحاصلات وفقاً لما هو مأمول من ذلكا. 
تعتبر تكنولوجيا التتعيع من الطرق الحديثة فى حفظ الأغذية والدراسات الفنية منواصلة منذ عقود حول إمكانيات حفظ كل من الأغذية النباتية الطازجة والجافة واللحوم والدواجن. وأجريت العديد من الدراسات الاقتصادية حول إمكانيات التطبيق الاقتصادي لهذه التقنية الحديثة ويعد من الأهمية السعى نحو تحسين التطبيق التجارى لهذه التقنية محلياً وذلك من خلال محوري تحسين قبول المستثر والمجتمع لإقامة المشروعات المتعلقة بهذه التقنية وهو ما تهنم به هذه الدراسة من خلال تقديم الروئا الاقتصادية لتطبيق هذه التكنولوجيا في مصر بما بسهم فى تحسين الوضع الاقتصادي والصحى والبيئى للمجتمع. مشكلة البحث

رغم ما أوضحته العديد من الدراسات السابقة حول أهمية التطبيق المحلى لتكنولوجيا التشعيع الغذائى من النواحي الفنية والصحية والبيئية

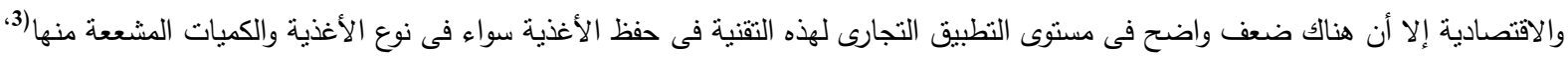
4). وذلك لضعف الدراسات الاقتصادية الخاصة بالتطبيق التجاري لهذه التقنية على مستوى المستثمر الخاص حملات التوعية للمواطنين بفوائد

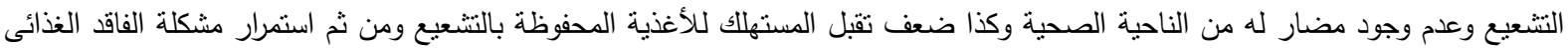
وكذللك الأضرار الصحية والبيئية والاقتصادية للحفظ الكيميائي وذللك لكل من الصادرات والواردات الغذائية فى مصر . الهدف من البحث:

استهدف البحث بصورة رئيسية إجراء التقييم الاقتصادي لطرق التغلب على مشكلات الفاقد الغذائي للتعرف على الإمكانيات الفنية لاستخدام تكنولوجيا الإشعاع وتقييمها من الناحية الاقتصادية، حفظ بعض الصادرات والواردات لحاصلات كل من: (القمح - الذرة الثنامية - البقوليات

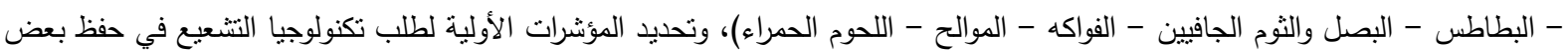
الصادرات والواردات الغذائية.

اعتمدت الدراسة على أسلوب التحليل الوصفي والكمي لدراسة الأهمية الاقتصادية لتقنية حفظ الصادرات والواردات الغذائية المصرية

بالتشعيع من خلال تقديم الدراسات الخاصة بالمستثمر الخاص والمجتمع. وقد نم ذلك من خلال المنهجية المعتمدة من البنك الدولى لدراسات

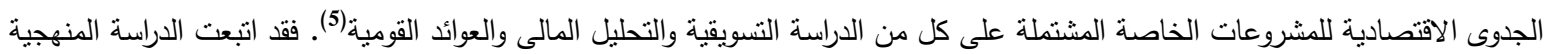

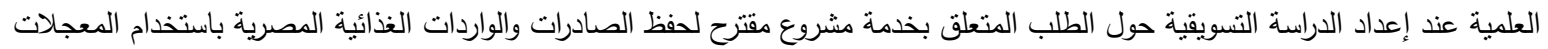
الإكترونية وذللك من خلال النموذج الاحصائى المناسب لتحديد الطلب المستقبلى المنوقع على خدمة حفظ الصادرات والواردات الغذائية المصرية بالمعجلات الإكترونية وكذلك اشتمل البحث على تحديد النموذج الأمثل للمعجل الإكترونى لحفظ الصادرات والواردات الغذائية المصرية من حيث النوع والقوة. واشتمل التحليل المالى للمشروع المقترح على حساب كل من التكاليف ووضع النظام النسعيرى المناسب لخدمة التشعيع والعوائد وتقويم

الربحية التجارية للمشروع وكذلك تقويم العوائد القومية المترتبة على استخدام تقنية حفظ الصادرات والواردات المصرية بالطاقة الإكترونية. مصادر البيانات اعتمد البحث على البيانات الثانوية الواردة من كل: البات - الجهاز المركزى للتعبئة والاحصاء (الكتاب السنوى) التجارة الخارجية التهات - هيئة الطاقة الذرية المصرية - المركز القومى لبحوث وتكنولوجيا الإشعاع - قسم بحوث تشعيع الأغذية - معمل اقتصاديات تتعيع الأغذية. - منظمة الأغذية والزراعة التابعة للأمم المتحدة (الفاو). - منظمة الصحة العالمية. - الوكالة الدولية للطاقة الذربة. - المراجع المتخصصة فى الدراسات الفنية والتسويقية والمالية والاقتصادية. - وحدة المعجل الإلكترونى - هيئة الطاقة الذرية. - شبكة المعلومات الدولية. اثتمل البحث على ثلاثة أقسام على النحو التالي: أولاً: الإمكانيات الفنية لاستخدام تكنولوجيا النتعيع فى حفظ بعض الصادرات لهات والواردات الغذائية المصرية 
ثانياً: الطلب المستقبلي المتوقع على استخدام تكنولوجيا التشعيع في حفظ بعض الصادرات والواردات الغذائية ثالثاً: الجدوى المالية والعوائد القومية لاستخدام تكنولوجيا التشعيع في حفظ بعض الصادرات والواردات الغذائية

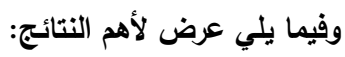
أولاً: الإمكانيات القنية لاستخدام تكنولوجيا التثعيع فى حفظ بعض الصادرات الصات والواردات الغذائية المصرية. - إمكانية استخدام تكنولوجيا التشعيع فى حفظ الحبوب (القمح، الأرة، البقوليات) يتم تثـعيع الحبوب ومنتجاتها كالقمح، الذرة، الأرز ، الثــعير، بغرض تطهيرها من الحشـرات، ولتحقيق ذلك نسـتخدم جرعات تشـعيعية تتراوح بين 0.2 إلى 0.5 كيلو جراى. وتمثل الحشــرات مشــكلة كبيرة أثثاء مرحلة تخزين الحبوب والبذور بأنواعها، وفى العادة يتم تطهير الحبوب

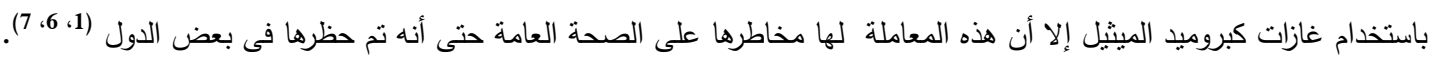
- إمكانية استخدام تكنولوجيا التشعيع فى حفظ محصول البطاطس.

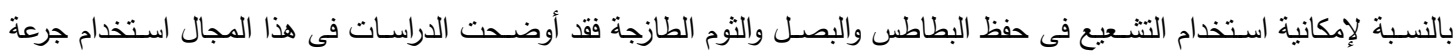
تثـعيعية 0.15 ك. جراى ثم الحفظ تحت ظروف الغرفة العادية يؤدى إلى تثبيط التزريع كأحد أهم المشـاكل التخزينية لهذه المحاصـيل مع مقاومة التعفن وتكوين الجذور العرضية والتكرمش وإطالة مدة الحفظ إلى نحو 6 شهور (1، 8). - إمكانية استخدام تكنولوجيا التشعيع في حفظ ثمار الفواكه.

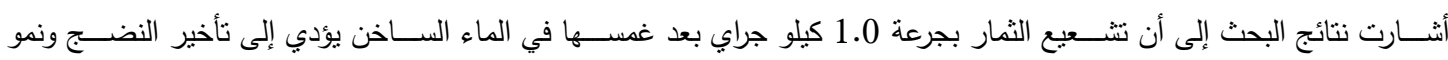

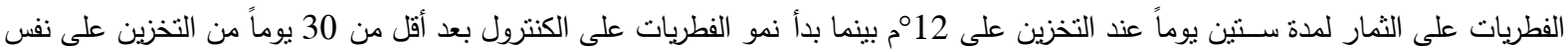

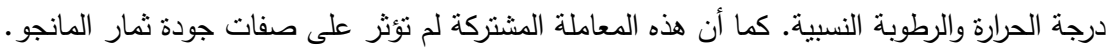
- إمكانية استخدام تكنولوجيا التشعيع لازالة ملوثات الفواكة ذات النواة الحجرية. تصـاب الفاكهة ذات النواة الحجرية مثل الخوخ والمشـشش والبرقوق بنوعين اسـاسـيين من الفطريات التى تسـبب العفن البنى للنمار قبل

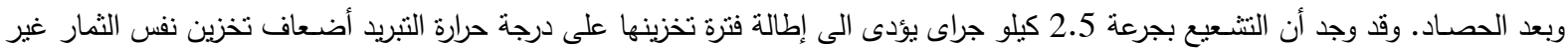
المعالجة بالإشعاع(1، 2).

- إمكانية استخدام تكنولوجيا التشعيع فى حفظ البصل والثوم الجافين.

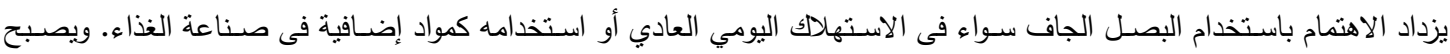

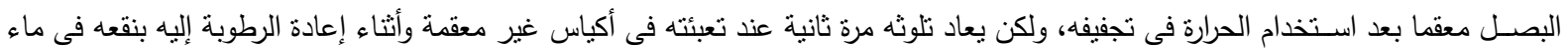

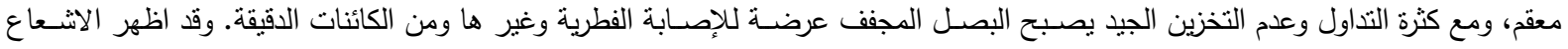
أهمية كبيرة فى مقاومة الميكروبات، حيث أن تعرض البصــل المجف الى جرعات (1-2 كيلو جراى) تكون كافية لخفض التلوث الميكروبى وأن

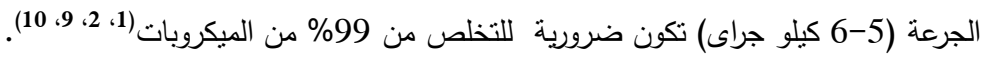

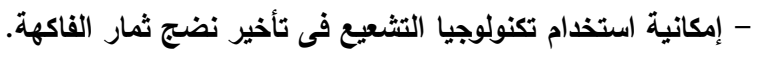

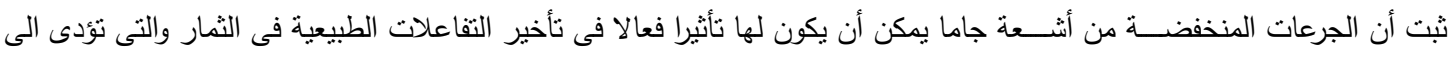

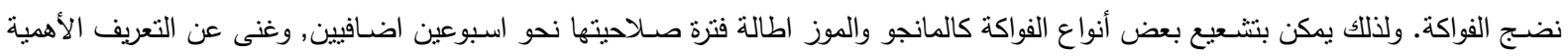
الاقتصـادية والميزة التصـديرية النسبية لهذه الثمار • وهكذا بمكن تحسين التجارة الداخلية للمانجو والموز وكذلك تثـجيع صـادراتها لاهميتها التجارية

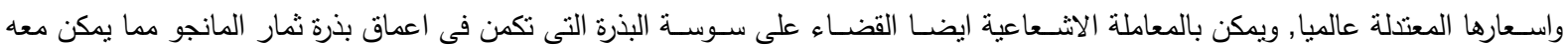
تجنب مشاكل الحجر الصحى فى موانئ الدول المستوردة(1)، 2. - إمكانية استخدام تكنولوجيا التثعيع فى حفظ التهوم التئ التمراء. يحدث تلوث داخلى وخارجى للذبائح بعدد كبير من الأحياء الدقيقة بعضها بسبب الفساد وبعضها الأخر يسبب أمراض، فعند نزع احثاء الدواجن بعد الذبح نزال اعداد كبيرة من الميكروبات الداخلية, وتظل الذبيحة ملوثة خارجيا ونتزايد اعداد الميكروبات الملوثة للاواجن خلادل عمليات

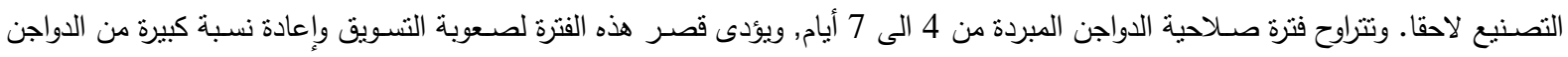

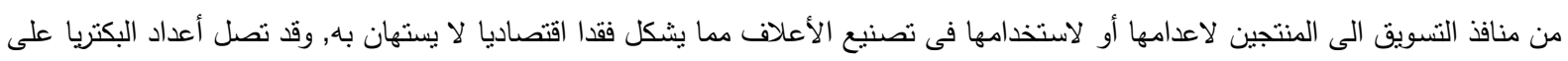

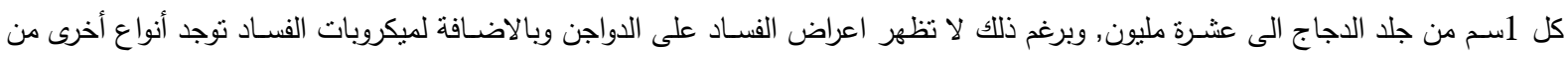

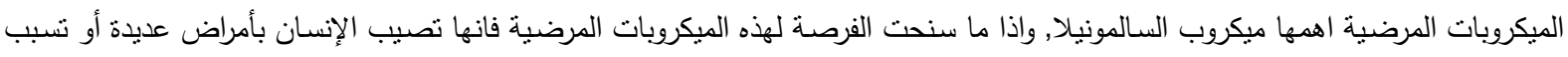

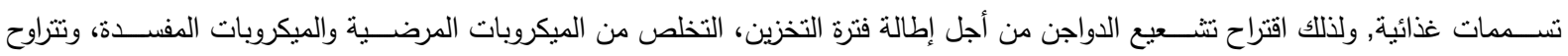
الجرعات الإشعاعية لتشعيع الدواجن من 3-7 كيلو جراى ويحدد الجرعة المناسبة الهدف المطلوب تحقيقه من التشعيع(1، 2). 


\section{ثانياً: الطلب المستقبلي المتوقع على استخدام تكنولوجيا التثعيع في حفظ بعض الصادرات والواردات الظذائية}

\begin{tabular}{|c|c|c|c|c|c|c|c|c|c|}
\hline \multirow{3}{*}{ الحمراء } & \multicolumn{4}{|c|}{ (مليون طن) } & \multicolumn{5}{|c|}{ جدول (1): الكميات الخاصة لبعض الصادرات والواردات الغذائية } \\
\hline & 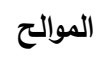 & الفواكه & 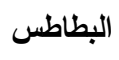 & 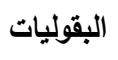 & 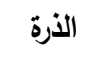 & القمح & الأعشاب & 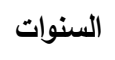 & • \\
\hline & & & & & 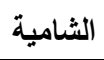 & & الطبية & & \\
\hline 0.19 & 0.24 & 0.06 & 0.39 & 0.53 & 5.098 & 5.688 & 0.270 & 2005 & 1 \\
\hline 0.3 & 0.31 & 0.08 & 0.37 & 0.57 & 3.769 & 5.817 & 0.385 & 2006 & 2 \\
\hline 0.31 & 0.3 & 0.11 & 0.39 & 0.46 & 4.474 & 5.916 & 0.187 & 2007 & 3 \\
\hline 0.4 & 0.52 & 0.27 & 0.45 & 0.77 & 5.08 & 7.381 & 0.235 & 2008 & 4 \\
\hline 0.13 & 0.88 & 0.19 & 0.25 & 0.46 & 1.88 & 4.061 & 0.332 & 2009 & 5 \\
\hline 0.2 & 0.89 & 0.37 & 0.3 & 0.46 & 5.58 & 9.805 & 0.364 & 2010 & 6 \\
\hline 0.21 & 1.08 & 0.69 & 0.65 & 0.46 & 6.892 & 9.804 & 0.366 & 2011 & 7 \\
\hline 0.21 & 1.08 & 0.21 & 0.77 & 0.49 & 6.28 & 9.884 & 0.381 & 2012 & 8 \\
\hline 0.31 & 1.24 & 0.46 & 0.88 & 0.67 & 6.17 & 9.970 & 0.385 & 2013 & 9 \\
\hline 0.35 & 0.91 & 0.35 & 0.7 & 0.45 & 4.27 & 8.105 & 0.393 & 2014 & 10 \\
\hline 0.35 & 0.99 & 0.38 & 0.8 & 0.49 & 5.04 & 8.982 & 0.396 & 2015 & 11 \\
\hline 0.37 & 1.25 & 0.41 & 0.8 & 0.52 & 5.32 & 11.8 & 0.399 & 2016 & 12 \\
\hline 0.38 & 1.29 & 0.44 & 0.81 & 0.52 & 5.45 & 9.45 & 0.402 & 2017 & 13 \\
\hline
\end{tabular}

جدول (2): معادلات الاتجاه الزمني لبعض الصادرات والواردات الذذائية

\begin{tabular}{|c|c|c|c|c|c|c|c|}
\hline $\mathbf{P}_{\mathrm{b}}$ & $P_{a}$ & $P_{f}$ & $F$ & $\mathbf{R}^{2}$ & المعادلة & المحصول & المعادلة \\
\hline 0.11 & 10.5 & 0.11 & 3.1 & 0.22 & $y=7.2+0.15 x$ & المعادلة (1) & 1 \\
\hline 0.7 & 7.5 & 0.7 & 0.16 & 0.01 & $y=7.1-0.03 x$ & الذرة الثـامية & 2 \\
\hline 0.8 & 8.9 & 0.8 & 0.06 & 0.01 & $y=2.9-0.01 x$ & $\begin{array}{c}\text { البقوليات المعادلة (3) } \\
\text { البقات }\end{array}$ & 3 \\
\hline 8.1 & 4.8 & 8.1 & 15.4 & 0.9 & $y=0.74+0.18 x$ & البصل والثوم الجافيين & 4 \\
\hline 0.0005 & 0.9 & 0.0005 & 23.7 & 0.7 & $y=0.1+0.33 x$ & البطاطس البطلة (5) & 5 \\
\hline 0.9 & 6.7 & 0.9 & 0.02 & 0.001 & $y=8.4-0.008 x$ & المعادلة (6) الفواكه & 6 \\
\hline 0.009 & 3.2 & 0.009 & 9.6 & 0.46 & $y=2.9+0.13 x$ & المعادلة (7) & 7 \\
\hline
\end{tabular}


جدول (3): الطلب المستقبلي المتوقع على استخدام تكنولوجيا النتعيع في حفظ بعض الصادرات والواردات الغذائية

(مليون طن)

م السنوات الأعثاب الطبية

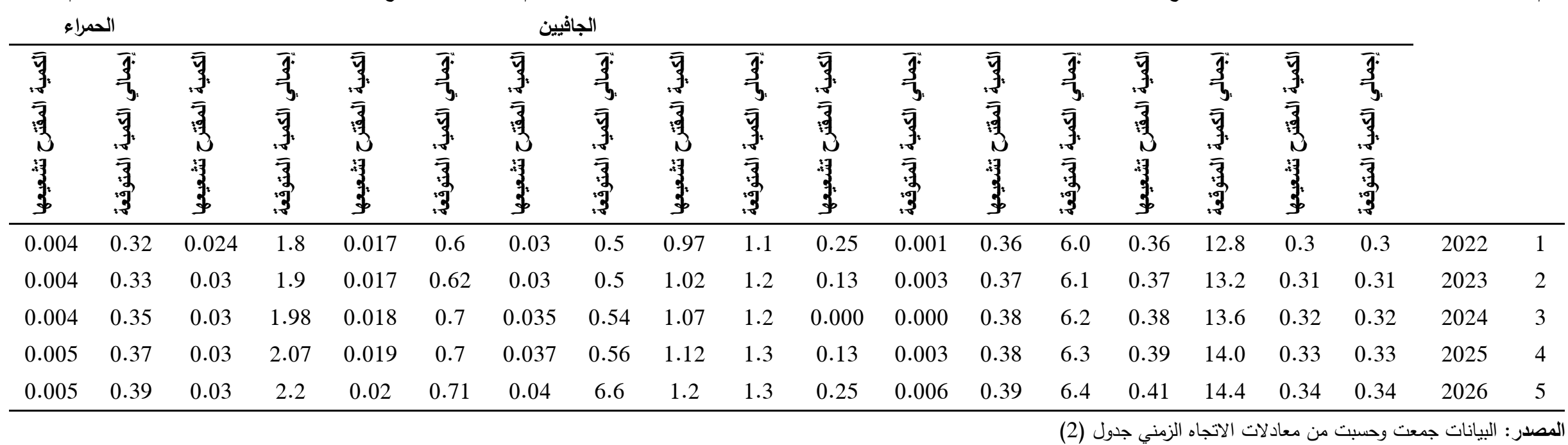


تحليد النموذج الأمثل لوحدة تكنولوجيا التشعيع لحفظ بعض الصادرات والواردات الغذائية

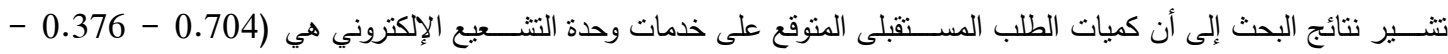

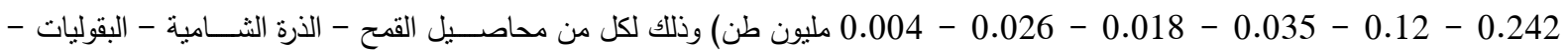
البطاطس - البصل والثوم الجافين - الفاكهة - الموالح - اللحوم الحمراء - الأعشاب الطبية المشععة في مصر تجارياً على التوالى وذلك كمتوسط لسنوات 2022 : 2026 [جدول 3]. وحتى يتسنى تحديد قوة المصدر المشع فإن ذلك يتطلب تحديد كل من: - الكمية الإجمالية من الأغذية المطلوب تشعيعها.

$$
\text { - عدد ساعات النتخغيل. }
$$

- الجرعة التشعيعية المطلوبة للأغذية.

ونظراً لأن جرعات الأغذية مختلفة بين 0.5 إلى 5 ك.جراى فإن ذلك يتطلب تحديد كمية إجمالية واحدة بجرعة واحدة افتراضـــياً ويتم ذلك من خلال تحديد الكمبة المطلوب تتـــعيعها من كل محصـــول بجرعته الأصــلية وما يعادلها من كمية الغذاء بجرعة 1 ك.جراى فمثناً كمية

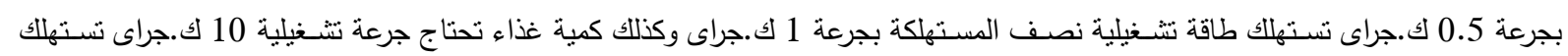

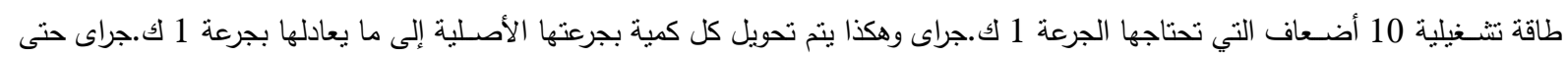
ينسنى حساب قوة المعل المناسب وهذا مع استمرار حصول كل غذاء على الجرعة النتعيعية الخاصة بها عملياً.

الكمية المعادلة بالجرعة 1 ك. جراى = الكمية الإجمالية × الجرعة الأصلية معادلة رقم (8) بالجرعة الأصلية

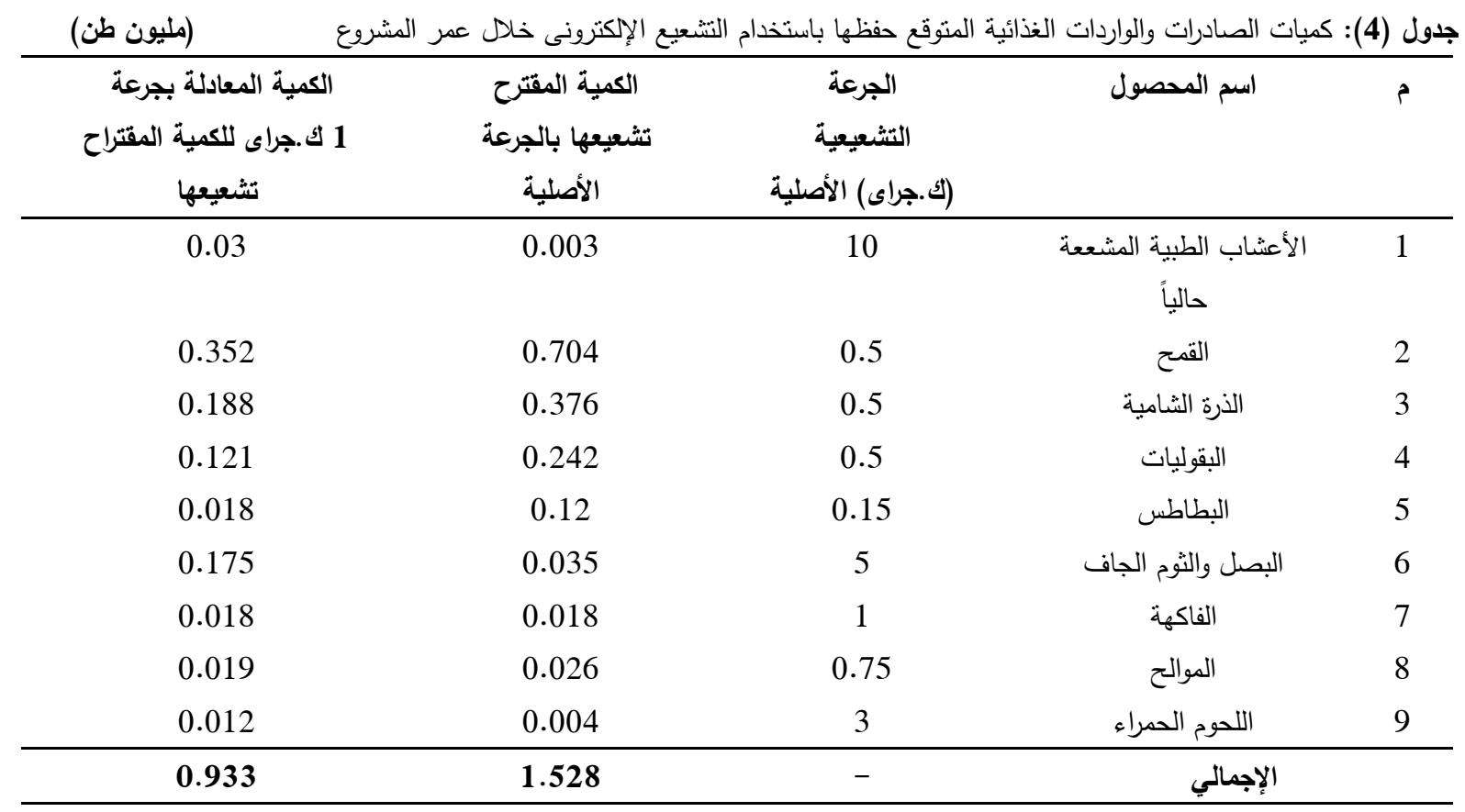

المصدر: جدول (3) ، معادلة (8)

وباســتخدام المعادلة رقم (9) ووفقاً لبيانات جدول (4) فإن قوة المعجل الإككترونى المطلوبة لتتـــعيع كمية قدرها 1.528 مليون طن

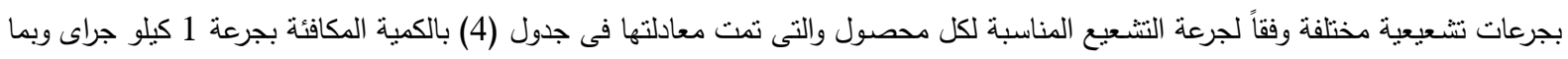

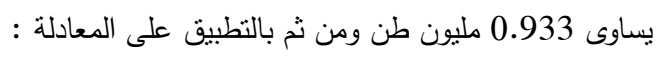

معادلة رقم (9)

ق = ك × ج / 360 × ف

حيث أن ق: قوة المعجل المطلوبة بالكيلو وات 
ك: الكمية المقترح تشعيعها بالكيلوجرام/ساعة

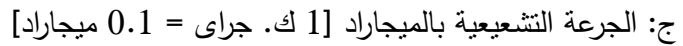

ف: كفاءة النشعيع

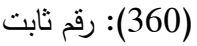

الكمية المقترح تشعيعها سنوياً بالكيلوجرام / ساعة

$129583.33=7200 / 933000000=$

وحيث أن كفاءة التشعيع 0.4 ، الجرعة النتعيعية 1 كيلوجراى = 0.1 ميجاراد.

ومن ثم فإن قوة المعجل الإكترونى المطلوبة بالكيلووات لتشـعيع كمية من الصـادرات والواردات الغذائية قدرها 0.933 مليون طن بجرعة

تشعيعية 1كيلوجراى

( 90 = 90 × 360) / $(0.1 \times 129583.33)=$

ومن ثم فإن مواصفات وحدة التشعيع المطلوبة لهذه الدراسة هى معجل الكترونى بقوة 10 ميجافولت، 90 كيلووات.

ثالثاً: الجدوى المالية وإلعوائد القومية لاستخدام تكنولوجيا التشعيع في حفظ بعض الصادرات والتواردات الفذائية

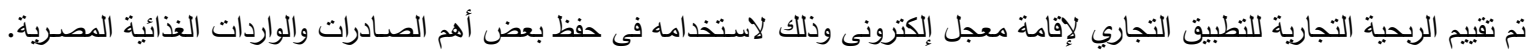

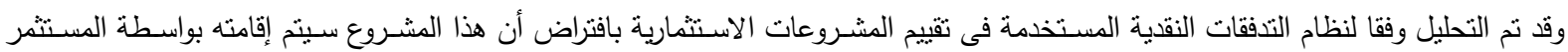
الخاص بالإضافة إلى دراسة العوائد القومية بناءاً على المعطيات الآتية:

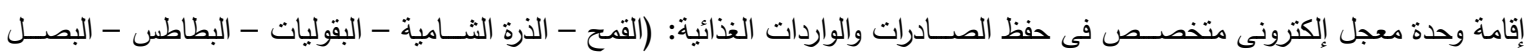

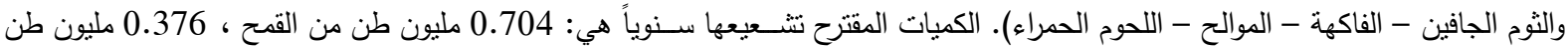
من الذرة الثـامية ، 0.242 مليون طن من البقوليات ، 0.12 مليون طن من البطاطس ، 0.035 مليون طن من البصل والثوم الجاف ، 0.018 مليون طن من الفاكهة (المشــش - البرقوق - الكمثرى - المانجو - الرمان - اللوز) ، 0.026 مليون طن من الموالح ، 0.004 مليون طن من اللحوم الحمراء بجرعة 1 ك. جراى. مئ. - الجرعات النتـعيعية المسـتخدمة للصـادرات والواردات: 0.5 كيلو جراي لمحاصـيل (القمح - الذرة الثـامية - البقوليات) - 0.15 كيلو جراى لمحصــل البطاطس الطازجة - 5 كبلو جراى لمحاصـيل البصـل والثوم الجافين - 1 كبلو جراى لمحاصـيل الفاكهة- 0.75 كيلو جراى لمحاصيل الموالح - 3 كيلو جراى للحوم الحمراء. - نوع وحدة التشعيع: معجل إلكتروني بطاقة 10 ميجا فولت - 90 كيلو وات التوات - عدد ساعات النتغيل: 7200 ساعة/سنوياً - الوحدة النقدية المستخدمة: الجنيه المصرى - الضرائب : 22\% بدءا من السنة النتخيلية الثامنة حيث أن المشروع معفى من الضرائب الخمس سنوات النشغيلية الأولى بالإضافة إلى عامى التأسيس. - معايير الربحية التجارية المستخدمة:

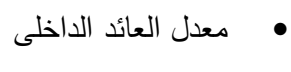

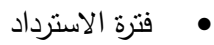

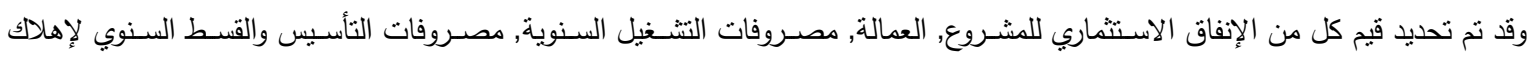
واستهلاك الأصسول الرأسمالية للمشروع. وكذلك تم وضـع نظام تسعبرى لوحدة التشـعيع ثم إعداد جداول التدفق النقدي للمشروع لتحديد عائد الربحية

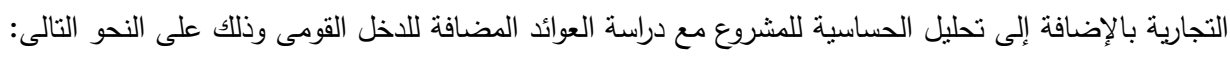
أ- تحليل التكاليف لاستخدام المعجل الإكتروني في حفظ بعض الصادرات الصات والواردات الغذائية. ب- سعر تتعيع الطن والإيراد السنوي. ج- تقويم الربحية التجارية. د- العوائد القومية. 
أ- تحليل التكاليف لاستخدام المعجل الإكتروني في حفظ بعض الصادرات والواردات الغذائية.

\begin{tabular}{|c|c|c|}
\hline & \multicolumn{2}{|c|}{ جدول (5) الانفاق الاستثمارى } \\
\hline القيمة المالية (مليون جنيه) & 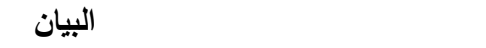 & 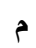 \\
\hline 4 & الأرض(1) & 1 \\
\hline 42.02 & المعجل الإلكترونى شاملاً الثحن والجمارك & 2 \\
\hline 5 & الحواجز الخرسانية(2) والمبانى & 3 \\
\hline 0.3 & مصروفات ما قبل التشغيل & 5 \\
\hline 1.047 & رأس المال العامل(3) & 6 \\
\hline 0.84 & & 7 \\
\hline 56.50 & تياطى نقدى عينى 5\% & \\
\hline
\end{tabular}

المصدر: معمل اقتصاديات تثعيع الأغذية - قسم بحوث تثعيع الأغذية.

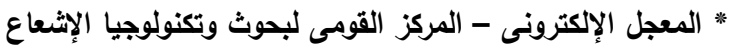

البيانات جمعت وحسبت.

(1) مساحة الأرض: 2000م2 بسعر المبات وحنز 2000جم.

(2) الحواجز الخرسانية لمنع التسرب الإثعاعى.

(3) رأس المال العامل: ح 5 شهور من مصروفات التشغيل السنوية للسنة الثالثة.

جلول (6) تكلفة العمالة السنوية

\begin{tabular}{|c|c|c|c|c|}
\hline الأجر السنوي مليون/جنيه & الأجر الشهري & عدد & البيان & p \\
\hline 0.108 & 4500 & 2 & | الإدارة العليا & 1 \\
\hline 0.072 & 1500 & 4 & | الإدارة المتوسطة & 2 \\
\hline 0.144 & 6000 & 2 & | العلميين & 3 \\
\hline 0.192 & 4000 & 4 & 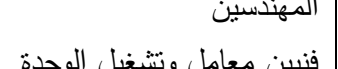 & 4 \\
\hline 0.1296 & 1200 & 9 & أمن وسائقين - & 5 \\
\hline 0.096 & 1000 & 8 & خدمات شحن وتفريغ & 6 \\
\hline 0.0432 & 900 & 4 & & 7 \\
\hline 0.785 & & 33 & & الإجما \\
\hline
\end{tabular}

\begin{tabular}{|c|c|c|c|c|c|c|c|c|c|c|}
\hline \multicolumn{4}{|c|}{ مليون جنيه } & \multicolumn{7}{|c|}{ جدول (7) مصروفات التشغيل السنوية } \\
\hline \multicolumn{9}{|c|}{ 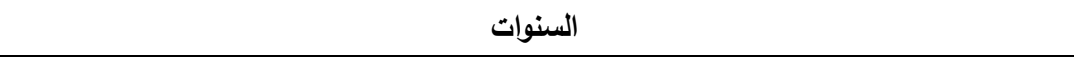 } & \multirow[t]{2}{*}{ 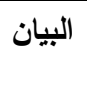 } & \multirow[t]{2}{*}{ p } \\
\hline 9 & 8 & 7 & 6 & 5 & 4 & 3 & 2 & 1 & & \\
\hline
\end{tabular}




\begin{tabular}{|c|c|c|c|c|c|c|c|c|c|c|}
\hline 0.785 & 0.785 & 0.785 & 0.785 & 0.785 & 0.785 & 0.785 & & & الأجور والرواتب(1) & 1 \\
\hline 0.58 & 0.58 & 0.58 & 0.58 & 0.58 & 0.58 & 0.58 & - & - & & 2 \\
\hline 0.84 & 0.84 & 0.84 & 0.84 & 0.84 & 0.84 & - & - & - & قالصيانة(3) & 3 \\
\hline 1.26 & 1.26 & 1.26 & 1.26 & 1.26 & - & - & - & - & دعاية وترويج & 4 \\
\hline 0.5 & 0.5 & 0.5 & 0.5 & 0.5 & 0.5 & 0.5 & 0.5 & 0.5 & & 5 \\
\hline 4.16 & 4.16 & 4.16 & 4.16 & 4.16 & 2.84 & 1.958 & 0.53 & 0.53 & جمالى مع احتياطى 5\% & \\
\hline
\end{tabular}

(1) أضيفت الأجور والرواتب ضمن مصروفات ما قبل النتخيل فى السنة الأولى والثانية.

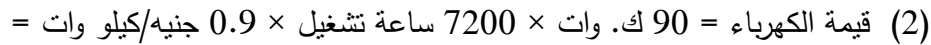

(3) الصيانة : 2\% من قيمة الاجمالية للمعجل.

جدول (8) مصروفات ما قبل التثغيل

\begin{tabular}{|c|c|c|}
\hline القيمة (مليون/جنيه) & البيان & م \\
\hline 0.247 & الأجور والرواتب(1) & 1 \\
\hline 0.150 & دراسات & 2 \\
\hline 0.150 & تصاريح & 3 \\
\hline 0.500 & دعاية وترويج & 4 \\
\hline
\end{tabular}

\begin{tabular}{c}
\hline 1.047 \\
\hline \\
$15^{(1)}$
\end{tabular}


جدول (9) القسط السنوي لإهلاك واستهلاك الأصول الرأسمالية

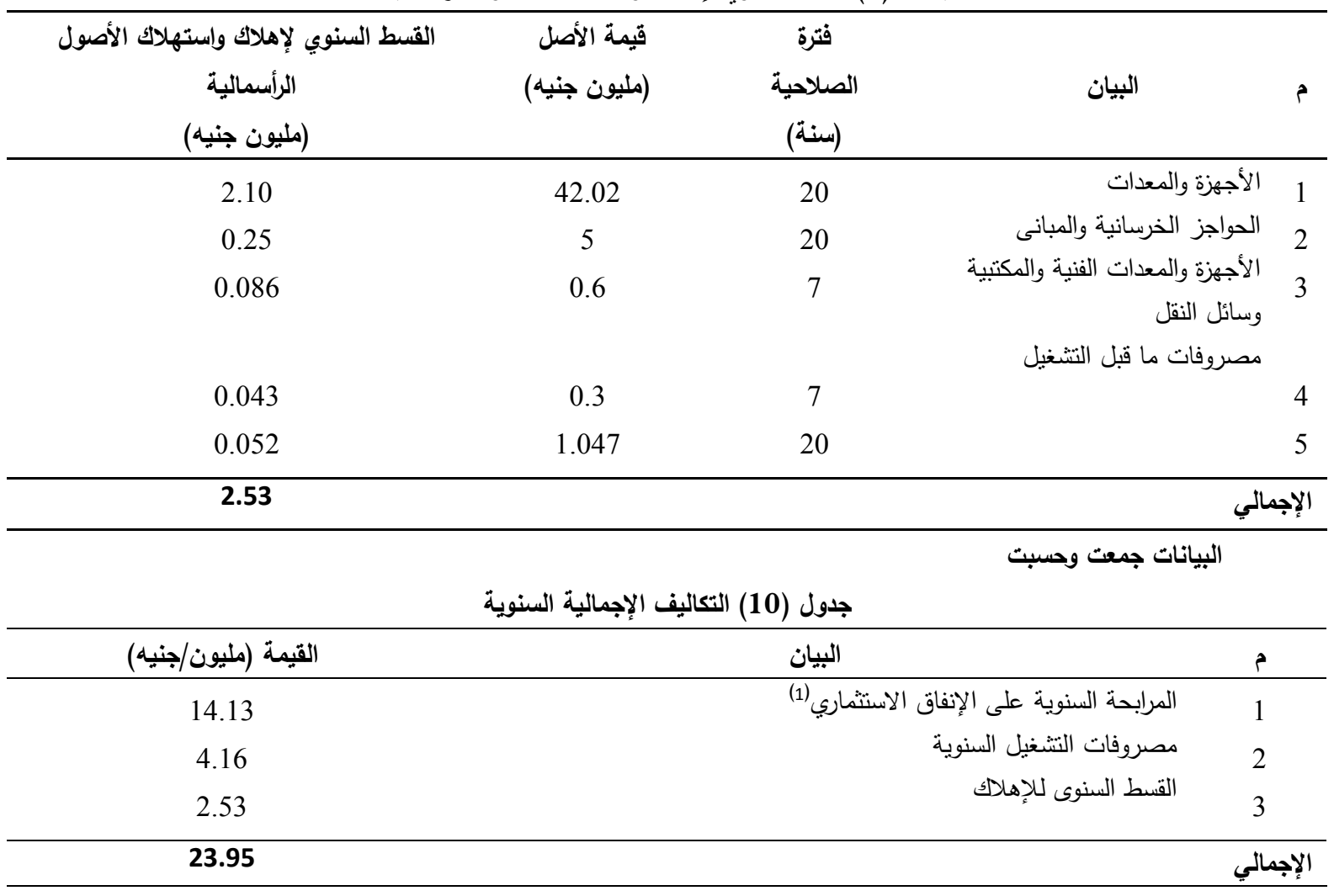

المصدر: البيانات جمعت وحسبت - من جداول (5)، (6)، (7)

(1) بما يعادل ح 25\% من الإنفاق الاستتماري

ب- سعر تشعيع الطن والإيراد السنوي:

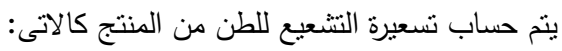

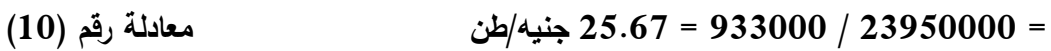

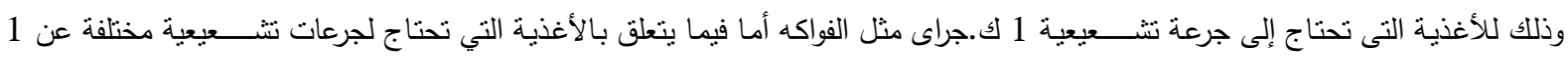

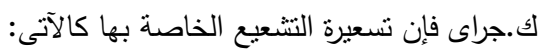

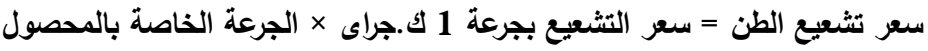
وبناءاً على المعادلة السابقة فقد تم حساب سـعر تشعيع الطن من كل محاصيل الحبوب والبطاطس والبصل والثوم الجافين والموالح والفواكه واللحوم الحمراء كالآتى: 1- سعر تثعيع القمح، البقوليات، الذرة الثشامية بجرعة تشعيعية قرها 0.5 ك.جراى:

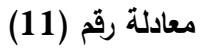
13 = 2 / 26 =

2- سعر تشعيع البطاطس الطازجة بجرعة تشعيعية قرها 0.15 ك. جراى:

معادلة رقم (12) - م) - م) 4 = 0.15 × $26=$ 3- سعر تشعيع البصل والثثوم الجافين بجرعة تشعيعية قرها 5 ك. جراى:

معادلة رقم (13) - (13) - م) 130 = 5 × 26 = 4- سعر تشعيع الفاكهة بجرعة تثعيعية قرها 1 ت. جراى: معادلة رقم (14) - م) 26 = 26 × 1 = 4- سعر تثعيع الموالح بجرعة تثعيعية قرها 0.75 ك. جراى: معادلة رقم (15) - م) ن 20 = 26 = 26 = 
5- سعر تثعيع مصنعات اللحوم الحمراء بجرعة تثعيعية قرها 3 ك. جراى:

معادلة رقم (16) م) م)

جنيه/طن 78 × $26=$

جدول (11) سعر تثعيع الطن من الصادرات والواردات الغذائية المصرية

\begin{tabular}{|c|c|c|c|c|}
\hline سعر التشعيع إلى (1) & سعر التشعيع بالجنيه & التشعيعية & المحصول & b \\
\hline$\% 0.18$ & 13 & 0.5 & القمح & 1 \\
\hline$\% 0.26$ & 13 & 0.5 & الذرة الثامية & 2 \\
\hline$\% 0.09$ & 13 & 0.5 & البقوليات & 3 \\
\hline$\% 0.1$ & 4 & 0.15 & البطاطس & 4 \\
\hline$\% 0.43$ & 130 & 5 & البصل والثوم الجاف & 5 \\
\hline$\% 0.26$ & 26 & 1 & الفاكهة & 6 \\
\hline$\% 0.4$ & 20 & 0.75 & 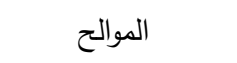 & 7 \\
\hline$\% 0.2$ & 78 & 3 & اللحوم الحمراء & 8 \\
\hline
\end{tabular}

المصدر: معادلات أرقم من (10 : 16)

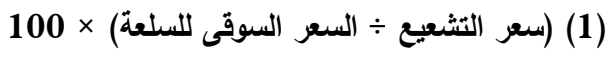

- الإيراد السنوي:

يتم حساب الإيراد السنوي كالآتي:-

الإيراد السنوي للمشروع = الكمية المطلوب تشعيعها سنوياً × سعر النشعيع معادلة رقم (17) $25.67 \times 933000=$

$23950110=$

ج- تقويم الريحية التجارية لاستخدام المعجلات الإكترونية في حفظ بعض الصادرات والواردات الغذائية 


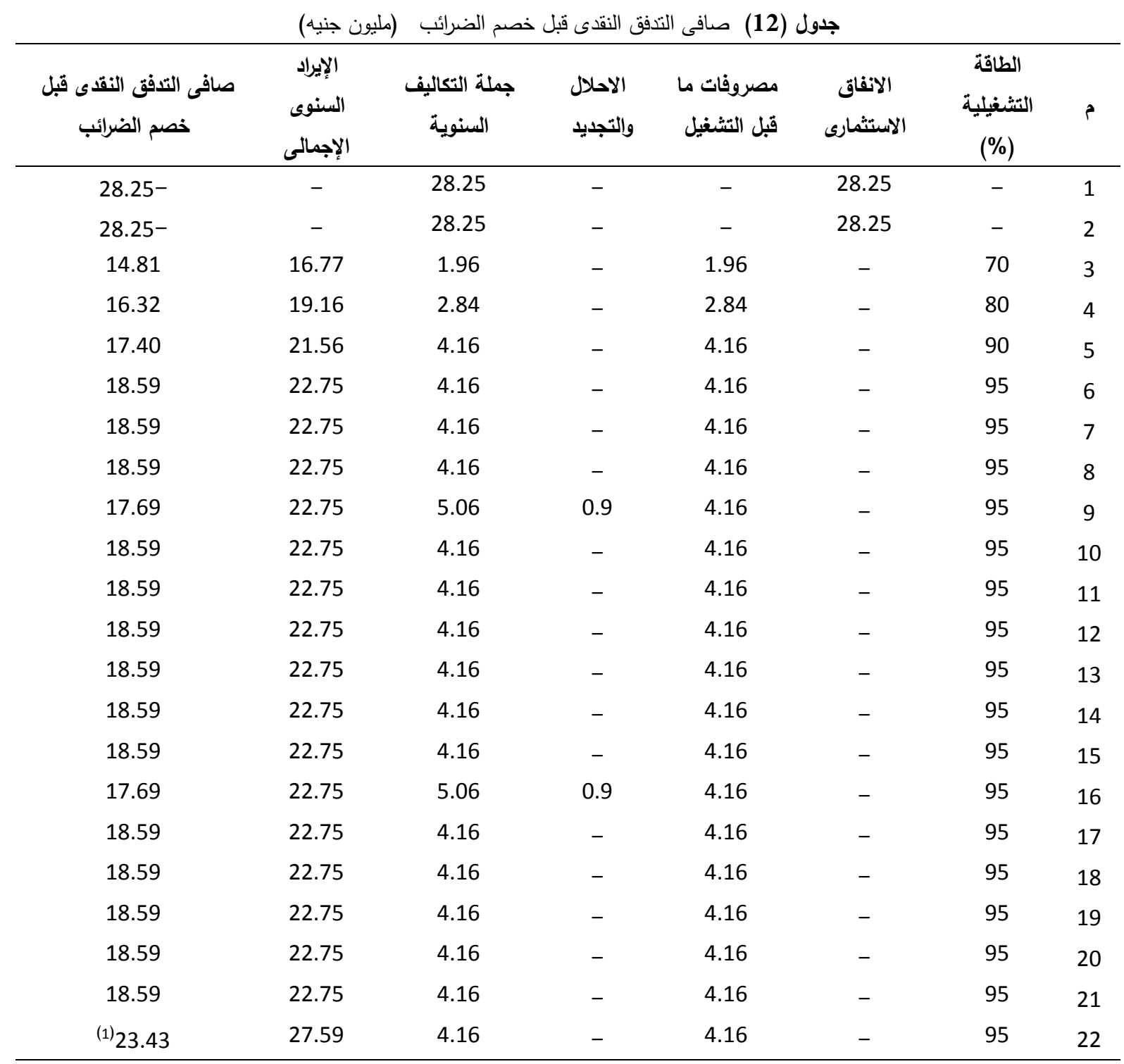

المصدر : البيانات جمعت وحسبت

(1) يضاف إلى إيراد السنة الأخيرة استرداد قيمة رأس المال العامل + استرداد قيمة الأرض

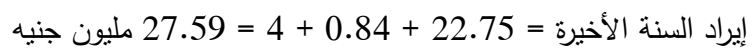




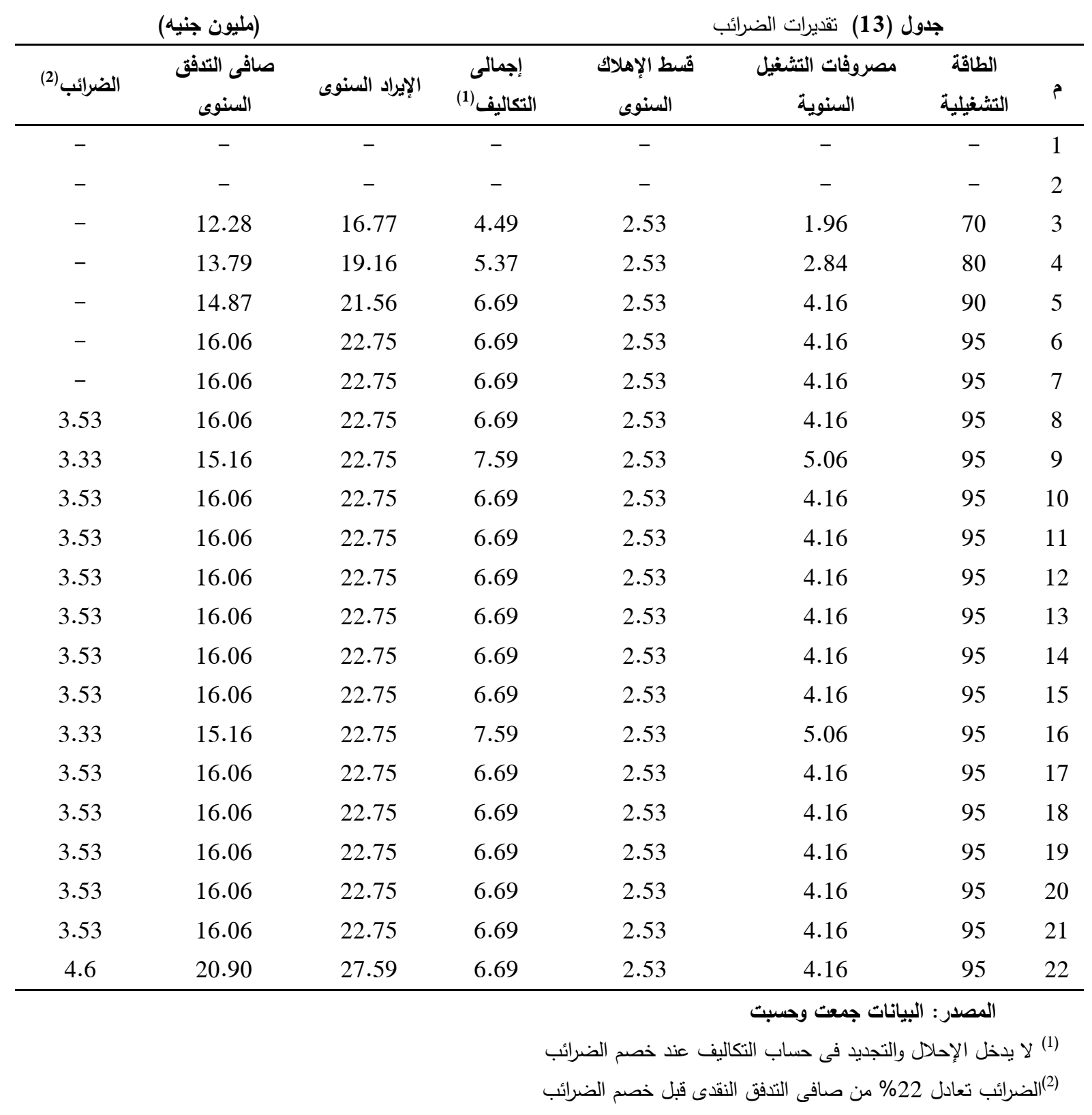




\begin{tabular}{|c|c|c|c|c|}
\hline & & ائب (مليون جنبه) & كسافى التدفق النقدى بـ & جدول (14) \\
\hline صافى التدفق النقدى & الضرائب & للمشروع قبل الضدفق النقائى(1) & $\begin{array}{c}\text { الطاقة التثغيلية } \\
\text { (\%) }\end{array}$ & p \\
\hline $28.25-$ & - & $28.25-$ & - & 1 \\
\hline $28.25-$ & - & $28.25-$ & - & 2 \\
\hline 14.81 & - & 14.81 & 70 & 3 \\
\hline 16.32 & - & 16.32 & 80 & 4 \\
\hline 17.40 & - & 17.40 & 90 & 5 \\
\hline 18.59 & - & 18.59 & 95 & 6 \\
\hline 18.59 & - & 18.59 & 95 & 7 \\
\hline 15.06 & 3.53 & 18.59 & 95 & 8 \\
\hline 14.16 & 3.53 & 17.69 & 95 & 9 \\
\hline 15.06 & 3.53 & 18.59 & 95 & 10 \\
\hline 15.06 & 3.53 & 18.59 & 95 & 11 \\
\hline 15.06 & 3.53 & 18.59 & 95 & 12 \\
\hline 15.06 & 3.53 & 18.59 & 95 & 13 \\
\hline 15.06 & 3.53 & 18.59 & 95 & 14 \\
\hline 15.06 & 3.53 & 18.59 & 95 & 15 \\
\hline 14.16 & 3.53 & 17.69 & 95 & 16 \\
\hline 15.06 & 3.53 & 18.59 & 95 & 17 \\
\hline 15.06 & 3.53 & 18.59 & 95 & 18 \\
\hline 15.06 & 3.53 & 18.59 & 95 & 19 \\
\hline 15.06 & 3.53 & 18.59 & 95 & 20 \\
\hline 15.06 & 3.53 & 18.59 & 95 & 21 \\
\hline 18.83 & 3.53 & 23.43 & 95 & 22 \\
\hline
\end{tabular}

(1) صافى التذفق النقدى الذى يخصم منه الضرائب هو صافى الندفق النقان النقى الأساسى والمحسوب بجدول (12) 


\begin{tabular}{|c|c|c|c|c|c|c|}
\hline صافى التدفق & بانخفاض 10 الإيراد السنوى & إلتكاليف & الضرائب & 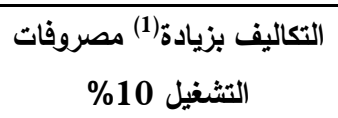 & 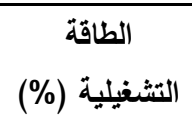 & p \\
\hline $28.25-$ & - & 28.25 & - & 28.25 & - & 1 \\
\hline $28.25-$ & - & 28.25 & - & 28.25 & - & 2 \\
\hline 12.93 & 15.09 & 2.16 & - & 2.16 & 70 & 3 \\
\hline 14.12 & 17.24 & 3.12 & - & 3.12 & 80 & 4 \\
\hline 14.82 & 19.40 & 4.58 & - & 4.58 & 90 & 5 \\
\hline 15.92 & 20.50 & 4.58 & - & 4.58 & 95 & 6 \\
\hline 15.92 & 20.50 & 4.58 & - & 4.58 & 95 & 7 \\
\hline 12.39 & 20.50 & 8.11 & 3.53 & 4.58 & 95 & 8 \\
\hline 10.81 & 20.50 & 9.69 & 3.53 & 6.16 & 95 & 9 \\
\hline 12.39 & 20.50 & 8.11 & 3.53 & 4.58 & 95 & 10 \\
\hline 12.39 & 20.50 & 8.11 & 3.53 & 4.58 & 95 & 11 \\
\hline 12.39 & 20.50 & 8.11 & 3.53 & 4.58 & 95 & 12 \\
\hline 12.39 & 20.50 & 8.11 & 3.53 & 4.58 & 95 & 13 \\
\hline 12.39 & 20.50 & 8.11 & 3.53 & 4.58 & 95 & 14 \\
\hline 12.39 & 20.50 & 8.11 & 3.53 & 4.58 & 95 & 15 \\
\hline 10.81 & 20.50 & 9.69 & 3.53 & 6.16 & 95 & 16 \\
\hline 12.39 & 20.50 & 8.11 & 3.53 & 4.58 & 95 & 17 \\
\hline 12.39 & 20.50 & 8.11 & 3.53 & 4.58 & 95 & 18 \\
\hline 12.39 & 20.50 & 8.11 & 3.53 & 4.58 & 95 & 19 \\
\hline 12.39 & 20.50 & 8.11 & 3.53 & 4.58 & 95 & 20 \\
\hline 12.39 & 20.50 & 8.11 & 3.53 & 4.58 & 95 & 21 \\
\hline 16.69 & 24.80 & 8.11 & 3.53 & 4.58 & 95 & 22 \\
\hline
\end{tabular}

(1) تتمل الاحلد والتجديد ومصروفات التثغيل والإنفاق الاستثمارى. 13. 14. 
جدول (16) نتائج تقويم الربحية التجارية لحفظ بعض الصادرات والواردات الغذائية المصرية باستخدام تكنولوجيا الإشعاع.

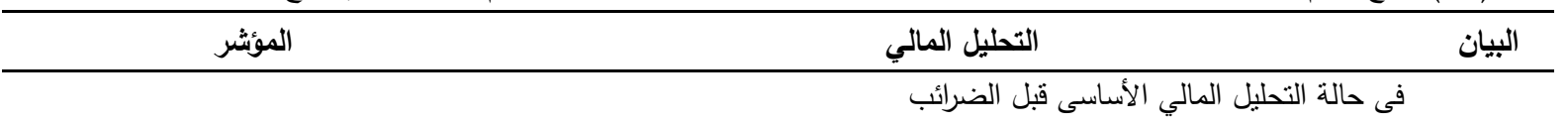

$\% 27$

3 سنوات و 4 أشهر

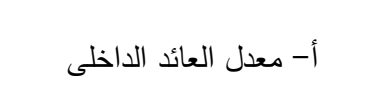

التحليل الأساسى بعدة الاسترداد الضرائب التباد

$\% 25$

4

ب أب أبائد الداخلى معدل

ب- فترة الاسترداد

تحليل الحساسية في حالة زيادة مصروفات التشغيل وانخفاض الإيرادات بنسبة 10\%

$\% 21$

4 سنوات و 4 أثنهر

ج أ- أ- معدل العائد الداخلى

ب- فترة الاسترداد

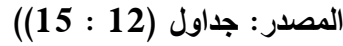


جدول (17): العوائد المتوقع إضافتها إلى الدخل القومى نتيجة حفظ بعض الصادرات والواردات الغذائية باستخدام تكنولوجيا المعجلات الإلكترونية .

\begin{tabular}{|c|c|c|c|c|c|c|c|c|c|c|}
\hline العوائد الصافية & العوائد الإجمالية & قيمة التكاليف الصحية & قيمة الفاقد & تكاليف تشعيع & 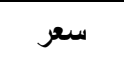 & الجرعة & قيمة الكمية & السعر & الكمية المقترح & \\
\hline المضافة للاخل & المضافة للاخل & والبيئية المتلافاه نتيجة & المتلافى نتيجة & الكمية & التشعيع & التشعيعية & المتوقع & السوقى للطن & تثعيعها بالطن & اسم المحصول \\
\hline القومى(3) & القومى(2) & التثعيع & التشعيع(4) & الإجمالية(1) & للطن & ك.جراى & تثعيعها & بالجنيه & (مليون جنيه) & \\
\hline (مليون جنيه) & (مليون جنيه) & بالمليون جنيه & بالمليون جنيه & بالمليون جنيه & (جنية) & & بالمليون جنيه & & & \\
\hline 188.1 & 197.2 & 98.6 & 98.6 & 9.15 & 13 & 0.05 & 4928 & 7000 & 0.704 & القمح \\
\hline 80.04 & 85.6 & 42.8 & 42.8 & 5.56 & 13 & 0.0 .5 & 2140 & 5000 & 0.428 & الذرة الثامية \\
\hline 142.05 & 145.2 & 72.6 & 72.6 & 3.15 & 13 & 0.05 & 3630 & 15000 & 0.242 & البقول \\
\hline 18.72 & 19.2 & 9.6 & 9.6 & 0.48 & 13 & 0.05 & 480 & 4000 & 0.12 & البطاطس \\
\hline 42.8 & 48 & 24 & 24 & 5.2 & 130 & 5 & 1200 & 30000 & 0.04 & البصل والثوم الجاف \\
\hline 87.43 & 88 & 44 & 44 & 0.572 & 26 & 1 & 2200 & 10000 & 0.022 & الفاكهة \\
\hline 35.5 & 39.4 & 19.7 & 19.7 & 3.94 & 20 & 0.75 & 985 & 5000 & 0.197 & الموالح \\
\hline 7.71 & 12 & 6 & 6 & 4.29 & 78 & 3 & 300 & 60000 & 0.005 & اللحوم الحمراء \\
\hline 602.35 & & & & & & & & & & الإجمالى \\
\hline
\end{tabular}

المصدر: البيانات جمعت وحسبت - جاول (3، البكاول 4، 11)

(1) تكاليف تشعيع الكمية الإجمالية = الكمية الإجمالية المطلوب تشعيعها × سعر التشعيع للطن

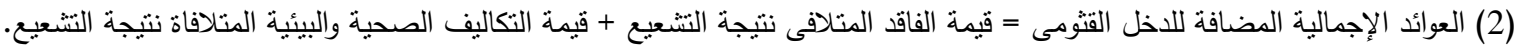

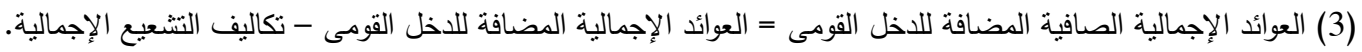

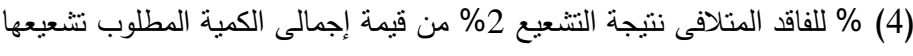

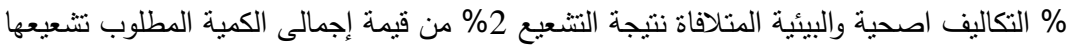


الفوائد التطبيقية

وفقاً للنتائج التي توصل إليها البحث فإنه هناك: - أهمية لتطبيق تكنولوجيا الإشعاع في حفظ بعض الصادرات والواردات الغذائية وذلك لإمكانية تكنولوجيا الإشعاع على خفض الفاقد الكمي

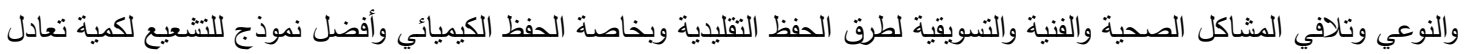
نحو 0.933 مليون طن من الصادرات والواردات الغذائية بجرعة قدرها 1 ك. جراي هو معجل إلكتروني بقوة 10 ميجا فولت، 90 كيلو وات مع انخفاض تكلفة الحفظ حيث تصل إلى نحو 13 جنية/طن لمحاصيل القمح والذرة والبقوليات، 4 جنية لمحصول البطاطس، 20 جنية للموالح والفاكهة 26 جنية والبصل والثوم الجافيين 13 جنية، 78 جنية للحوم الحمراء وهي تعادل نحو 18\%، 25\%، 0.1\%، 0.4\%، 0.26\%، 0.43\%، 0.2\% من السعر السوقي للأغذية السابقة على التوالي. - جدوى اقتصادية وتسويقية وذلك من خلال ما أظهرته نتائج البحث من إمكانية إقامة وحدات لحفظ الصادرات والواردات بالإشعاع حيث أثنارت الربحية التجارية إلى أن معدل العائد الداخلي 27\%، 25\%، 21\% وأن فترة الاسترداد نحو 3 سنوات و4 شهور، 4 سنوات، 4 سنوات و4 شهور في حالات التحليل الأساسي بدون ضرائب والتحليل بعد فرض الضرائب وتحليل الحساسية على التوالي. - أهمية الدعم الحكومي للنطبيق التجاري لتكنولوجيا التشعيع في حفظ الصادرات والواردات الغذائية حيث أنه بمكن أن تحقق عوائد صافية للاخل القومي قدرها 602 مليون جنية سنوياً عند حفظ كمية قدرها نحو 933 مليون طن بجرعة 1 ك. جراي.

1- شرباص، محمود نوفيق (1996): تكنولوجيا الإشعاع في الأغذية والزراعة - مركز تكنولوجيا الإثعاع - هيئة الطاقة الذرية - مصر . 2- حماد، على إبراهيم (2003): حفظ الأغذية بالتشعيع - مكتبة المعارف الحديثة - القاهرة. 3- الجميل، عصام الدين عبدالرحمن (1993): دراسة اقتصادية لحفظ الأغذية النباتية بالإثعاع في مصر ـ ـ رسالة ماجستير ـ قسم الاقتصاد

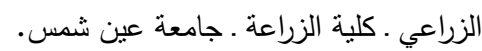
4- الجميل، عصام الدين عبدالرحمن (2002): دراسة اقتصادية لإمكانيات تطبيق تكنولوجيا التشعيع الغذائي في مصر - رسالة دكتوراه قسم الاقتصاد الزراعي - كلية الزراعة . جامعة عين شمس.

5- J.P Gettinger, (1972): "Analysis of Agricultural Projects". A World Bank Publication, Washington report No. UNN70.

6- عباس، فاطمة (1976): اقتصاديات تخزين الحبوب في ج•م•ع، رسالة ماسجتير - قسم الاقتصاد الزراعي - كلية الزراعة - جامعة عين

فؤاد، محمد طلعت وآخرون (1978): تأثثر الحبوب ومنتجاتها المعاملة بالإشعاع على الصحة العامة- التقرير النهائي لمشروع مكافحة الآفات التي تصيب المخزون في مصر - هيئة الطاقة الذرية المصرية. العدوي، أثجا محمود (1989): تأثثر أشعة جاما وبعض المركبات الفسيولوجية على تخزين البطاطس - رسالة دكتوراه - قسم البساتين -

محمود، عبداله عبداله السيد (1978): دراسات على تأثير المعاملات الكيميائية والإشعاعية أثثاء التخزين على القدرة التخزينية والمكونات الكيمبائية للبطاطس - رسالة دكتوراه - مركز بحوث الأغذية - أكاديمبة العلوم المجرية.

فرج، سراج الدين أحمد (1986): التأثثر الفسيولوجي لأثعة جاما على قابلية التخزين لمحصول الثثوم - رسالة دكتوراه - قسم البساتين - 


\title{
Economic and Marketing Aspects Related to Ways to Overcome the Problems of Food Losses for some Exports and Food Imports
}

\author{
Prof. Dr. Said Abbas Mohamed Rashad , Prof. Dr. Mahmoud Al-Sayed Rageh , \\ Prof. Dr. Essam A. El-Gameel \\ Ibrahim Mahmoud Mohammed Murad
}

\begin{abstract}
The aim of reducing the quantitative and qualitative losses the most important Egyptian exports and imports while avoiding health, environmental, marketing and economic problems is one of the main axes of the improvement of the local food situation. Due to the lack of some traditional methods of conservation, there has been an international and local approach to using conservation technology to prevent this deficiency and the importance of improving the application Commercialization of this technique was important to conduct such a study of technical feasibility, marketing, financial and national, where the study included three sections.

The first section deals with the technical possibilities of the use of food irradiation technology in the preservation of some exports and food imports (wheat, maize, legumes, potatoes, onions, garlic, fruits, citrus, red meat). In the second section, the preliminary indicators for the application of irradiation technology in the preservation of some exports and food imports were sought. The study indicated that the expected quantity is saved to the equivalent of 933 thousand tons per year with irradiated dose of $1 \mathrm{~kg}$. In the third section, the financial analysis was carried out, including the determination of investment expenditure, labor cost, annual operating specifications, pre-operating expenses, annual depreciation, total annual costs $(56.5,0.79,4.16,11.05,2.53) 10^{3}$ L.E The price of irradiation was more than $0.5 \%$ of the market price of any of the foods studied. The commercial profitability of irradiation has been evaluated. Save exports and imports and use cash flow tables where a The results of the analysis showed that the internal rate of return is $27 \%, 21 \%$, while the Pay Back period is 3.4 years, 4.4 years in both basic analysis and sensitivity analysis. The expected returns to the national income were analyzed as a result of keeping some exports and food imports using technology Irradiation as a result of reduction of losses and avoid the health and environmental problems of traditional conservation methods. The study showed that the expected return to income amounted to 602 million pounds annually.
\end{abstract}

